Special issue of the 2nd International Conference on Computational and Experimental Science and Engineering (ICCESEN 2015)

\title{
Nitrogen Source, an Important Determinant of Fatty Acid Accumulation and Profile in Scenedesmus obliquus
}

\author{
K. YilancioĞLU ${ }^{a, *}$, H.O. TeKin ${ }^{b}$ And S. CetineR ${ }^{c}$ \\ ${ }^{a}$ Üsküdar University, Faculty of Engineering and Natural Sciences, Bioengineering Dept., Istanbul, Turkey \\ ${ }^{b}$ Üsküdar University, Vocational School of Health Services, Radiotherapy Dept., Istanbul, Turkey \\ ${ }^{c}$ Sabanci University, Faculty of Engineering and Natural Sciences, Dept. of Biological Sciences and Bioengineering, \\ Istanbul, Turkey
}

\begin{abstract}
The potential of algae-based fuel technologies for manufacturing renewable biofuels has been attracting interest from the scientific community. Biomass productivity and cellular lipid content are important parameters affecting the feasibility of using algae oil for biodiesel production. This study compares utilization of $\mathrm{NaNO}_{3}, \mathrm{NH}_{4} \mathrm{Cl}$ and urea as different nitrogen sources in terms of their effects on biomass productivity, fatty acid profile and accumulation in Scenedesmus obliquus. Cellular lipid accumulation was analyzed by gravimetric, fluorometric, and flow-cytometric methods, besides collecting spectrophotometric data for biomass productivity analysis. In addition, fatty acid profiles were compared by using gas chromatography-mass spectrometry. The alga can utilize all tested nitrogen sources successfully however growth rates demonstrate differences. Gravimetric lipid content analysis showed approximately a $\approx 1.5$-fold increase in total lipid accumulation under $\mathrm{NH}_{4} \mathrm{Cl}$ regime when compared to that of $\mathrm{NaNO}_{3}$ and $\mathrm{a} \approx 2$-fold increase when compared to that of urea at the end of ten days cultivation course. Fatty acid profiles under different nitrogen regimes present variations especially under $\mathrm{NH}_{4} \mathrm{Cl}$ regime. Moreover, all lipid extracts mostly consist of saturated, straight- and branched-chain hydrocarbons of different chain lengths ranging from C16-C20 which grant a suitable profile for biodiesel production. Scenedesmus obliquus is a suitable species for biodiesel production. The results obtained from this study provide a better understanding of cultivation characteristics of this important species and support potential, future biodiesel production.
\end{abstract}

DOI: 10.12693/APhysPolA.130.428

PACS/topics: 88.20.fk, 87.14.Cc

\section{Introduction}

The global state of increasing energy consumption and demand pressurizes the scientific community to find new sustainable energy resources. Among different prospective options, biodiesel has recently garnered interest because of its environmental benefits and renewable characteristics.

The use of alkyl esters of long-chain fatty acids in diesel engines without expensive modifications makes biodiesel an attractive candidate when compared to other options such as hydrogen or solar power. Microalgae, due to their fast growth and small production area compared to other terrestrial plants, have been proposed as a very good potential feedstock of sustainable biodiesel production. Furthermore, using oilseed crops instead of algae for biofuel production creates a negative tension with food security because of the projected increased need for agricultural food production on the horizon [1].

Another desirable characteristic of algae is that environmental changes or stress conditions result in alterations in the lipid biosynthetic pathways and the formation and accumulation of increasing amounts of lipids

\footnotetext{
* corresponding author; e-mail:

kaan.yilancioglu@uskudar.edu.tr
}

[20-50\% dry cell weight (DCW)], generally in the form of triacylglycerol (TAG). Unlike other lipids, TAGs do not perform a structural role but mainly serve as a storage form of carbon and energy. After synthesis, TAGs are deposited in densely packed lipid bodies in the cytoplasm of algal cells. Therefore, after following the isolation of algal lipids, biodiesel can be produced simply by transesterification of the TAGs with methanol and a catalyzer, generally $\mathrm{NaOH}[2]$.

Many algal species are already known for their lipid contents and hence their potentials for use in the production of biofuel [3]. Examples of such algae are Botryococcus braunii [4], Nannochloropsis oculata [5], Dunaliella tertiolecta [6], Haematococcus pluvialis [7], and Chlorella vulgaris [8] in terms of the effects of nutrient deficiencies and different cultivation conditions on their lipid accumulation and biomass production rates. It is also known that different nitrogen sources can be successfully utilized by most of microalgae species [9]. Therefore, some nitrogen sources may promote higher lipid accumulation and different fatty acid profiles. However, limited information has been demonstrated to date.

According to a study the optimal biomass and lipid productivity, of $S$. obliquus were determined as $292.50 \mathrm{mg} \mathrm{L}^{-1}$ day $^{-1}, 78.73 \mathrm{mg} \mathrm{L}^{-1}$ day $^{-1}$ (38.9\% lipid content per dry weight of biomass), respectively [10]. In addition, under the nutrient-deficient condition, the 
micro-alga lipid was found mainly composed of C16C18 fatty acids (accounting for $89 \%$ of total fatty acids), a composition thought suitable for biodiesel production [10]. Another study analyzed the potential of $S$. obliquus for biodiesel production: according to the study, the lipid contents of experimental groups under nitrogen depleted conditions increased up to 40-fold higher when compared to that of control groups [11].

On the basis of previous findings, it is clearly stated that $S$. obliquus suggests itself as one of the most prominent candidate algal species for biodiesel production. Its high biomass and lipid productive, well-adaptive characteristics prompted us to choose $S$. obliquus in this study. Additional benefit of previous studies has led us to focus on our comparison of the effects of $\mathrm{NaNO}_{3}, \mathrm{NH}_{4} \mathrm{Cl}$ and urea as different nitrogen sources on growth, lipid profile and accumulation so as to attain a better understanding of cultivation characteristics of this important species and support potential, future biodiesel production.

\section{Materials and methods}

\subsection{Organisms and culture conditions}

S. obliquus UTEX 393 was obtained from the Culture Collection of Algae at the University of Texas at Austin, and maintained in modified bold $3 \mathrm{~N}$ growth medium prepared according to the instructions of the UTEX Culture Collection of Algae. Cultivations were done at $24^{\circ} \mathrm{C}, 150 \mathrm{rpm}$, with continuous illumination of $150 \mu \mathrm{mol} /\left(\mathrm{m}^{2} \mathrm{~s}\right)$ in batch cultures. The medium contains $5 \mathrm{mM}$ nitrogen by adding one of the different sources $\left(\mathrm{NaNO}_{3} /\right.$ urea $/ \mathrm{NH}_{4} \mathrm{Cl}$ ) along with $\mathrm{CaCl}_{2} \cdot 2 \mathrm{H}_{2} \mathrm{O} 0.17 \mathrm{mM}$, $\mathrm{MgSO}_{4} \cdot 7 \mathrm{H}_{2} \mathrm{O} 0.3 \mathrm{mM}, \mathrm{K}_{2} \mathrm{HPO}_{4} 0.43 \mathrm{mM}, \mathrm{KH}_{2} \mathrm{PO}_{4}$ $1.29 \mathrm{mM}, \mathrm{NaCl} 0.43 \mathrm{mM}, \mathrm{Na}_{2}$ EDTA $2 \mathrm{H}_{2} \mathrm{O} 2 \mathrm{mM}$, $\mathrm{FeCl}_{3} \cdot 6 \mathrm{H}_{2} \mathrm{O} 0.36 \mathrm{mM}, \mathrm{MnCl}_{2} \cdot 4 \mathrm{H}_{2} \mathrm{O} 0.21 \mathrm{mM}, \mathrm{ZnCl}_{2}$ $0.037 \mathrm{mM}, \mathrm{CoCl}_{2} \cdot 6 \mathrm{H}_{2} \mathrm{O} 0.0084 \mathrm{mM}, \mathrm{Na}_{2} \mathrm{MoO}_{4} \cdot 2 \mathrm{H}_{2} \mathrm{O}$ $0.017 \mathrm{mM}$, vitamin $\mathrm{B}_{12} 0.1 \mathrm{mM}$, biotin $0.1 \mathrm{mM}$, thiamine $6.5 \mathrm{mM}$ and $5 \mathrm{mM} \mathrm{NaCO}_{3}$ was supplied as a carbon source.

\subsection{Effect of different nitrogen sources on growth and lipid accumulation}

To study the effect of different nitrogen sources on growth and lipid accumulation, algae cells were grown in media with different nitrogen sources. Growth was achieved by equimolar concentrations $(5 \mathrm{mM})$ of nitrogen by adding the appropriate amounts of urea, $\mathrm{NaNO}_{3}$ or $\mathrm{NH}_{4} \mathrm{Cl}$ in a cultivation medium. The experiments were done in triplicate, in $1 \mathrm{~L}$ Erlenmeyer glass flasks in $500 \mathrm{~mL}$ volume.

\subsection{Biomass measurement}

Biomasses were determined each day by measuring the optical density (OD) of samples at $600 \mathrm{~nm}$. Samples were diluted by a ratio of $1: 2$ to ensure that the measured $\mathrm{OD}_{600}$ values ranged in $0.2-0.6$. The correspondence between optical density and DCW was determined by plotting $\mathrm{OD}_{600}$ values against $\mathrm{DCW}$ of appropriate serial dilutions of samples with different biomass concentrations. On the basis of this noun, biomass concentration was calculated by multiplying $\mathrm{OD}_{600}$ values with 0.373 $\left(r^{2}=0.993\right)$. The conversion factor DCW of the samples was determined gravimetrically after centrifugation drying $(6,000 \mathrm{rpm}, 10 \mathrm{~min})$ of the algal cells collected from samples and washing twice with $\mathrm{dH}_{2} \mathrm{O}$.

\subsection{Growth analysis}

Specific growth rate was calculated according to the equation

$$
K^{\prime}=\ln \left(N_{2} / N_{1}\right) /\left(t_{2}-t_{1}\right),
$$

where $N_{1}$ and $N_{2}$ is biomass at $t_{1}$ and $t_{2}$, respectively $\left(t_{2}>t_{1}\right)$. Divisions per day and the generation or doubling time were calculated according to the equations below, once the specific growth rate was known divisions per day:

$$
\text { Div.day }{ }^{-1}=K^{\prime} / \ln 2,
$$

generation time:

$$
\text { Gen.t }=\text { Div.day }{ }^{-1} \text {. }
$$

\subsection{Extraction and measurements of lipid contents}

The lipid was extracted according to Bligh and Dyer wet extraction method. Briefly, to a $15 \mathrm{~mL}$ glass vial containing $100 \mathrm{mg}$ dried algal biomass, $2 \mathrm{~mL}$ methanol and $1 \mathrm{~mL}$ chloroform were added and kept for $24 \mathrm{~h}$ at $25^{\circ} \mathrm{C}$. The mixture was then vortexed for $5 \mathrm{~min} .1 \mathrm{~mL}$ of chloroform was again added, and the mixture shaken vigorously for $1 \mathrm{~min}$. Subsequently, $1.8 \mathrm{~mL}$ of distilled water was added and the mixture vortexed again for $2 \mathrm{~min}$. The aqueous and organic phases were separated by centrifugation for $10 \mathrm{~min}$ at 2,000 rpm. The lower (organic) phase was transferred into a previously weighed clean vial (V1). Evaporation occurred in a thermo-block at $95^{\circ} \mathrm{C}$, and the residue was further dried at $104^{\circ} \mathrm{C}$ for $30 \mathrm{~min}$. The weight of the vial was again recorded (V2). Lipid content was calculated by subtracting V1 from V2, and expressed as \% dcw.

\subsection{Micro plate nile red fluorescence assay}

A stock solution of nile red (NR) (Sigma, 72485) was prepared by adding $3 \mathrm{mg}$ of $\mathrm{NR}$ to $100 \mathrm{~mL}$ of acetone. The solution was kept in an opaque bottle and stored in the dark at $-20^{\circ} \mathrm{C}$. Algal cells cultivated with different nitrogen sources were transferred to $1.5 \mathrm{~mL}$ eppendorf tubes for $10 \mathrm{~min}$ centrifugation at $6,000 \mathrm{rpm}$, washed twice with $\mathrm{dH}_{2} \mathrm{O}$, and measured in a spectrophotometer at $600 \mathrm{~nm}$. Each sample was adjusted to an $\mathrm{OD}_{600}$ of 0.3 in a $1 \mathrm{~mL}$ final volume by dilution with $\mathrm{H}_{2} \mathrm{O} .5 \mu \mathrm{L}$ of nile red solution was added to each tube and well mixed, followed by 20 min incubation in dark. Finally, cellular neutral lipids were quantified using a 96-well microplate reader (SpectraMAX GEMINI XS) with an excitation wavelength of $485 \mathrm{~nm}$ and an emission wavelength of $595 \mathrm{~nm}$. 


\subsection{Flow cytometric analysis}

$5 \mu \mathrm{L}$ of a working solution of $\mathrm{NR}$ and acetone $(0.03 \mathrm{mg} / \mathrm{mL})$ was added to $1 \mathrm{~mL}$ of a cell suspension at an $\mathrm{OD}_{600}$ of 0.3 . This mixture was gently vortexed and incubated for $30 \mathrm{~min}$ at $37^{\circ} \mathrm{C}$ in darkness. NR uptake was determined with a BD-FACS Canto flow cytometer (Becton Dickinson Instruments), equipped with a $488 \mathrm{~nm}$ argon laser. Upon excitation by a $488 \mathrm{~nm}$ argon laser, NR exhibits intense yellow-gold fluorescence when dissolved in neutral lipids. The optical system used in the FACS Canto collects yellow and orange light (560$640 \mathrm{~nm}$, corresponding to neutral lipids). The fluorescence of NR-emission for neutral lipids was thus determined. Approximately 10,000 cells were analyzed using a log amplification of the fluorescent signal. Non-stained cells were used as an auto fluorescence control. Data were expressed as mean fluorescence intensity.

\subsection{Protein, chlorophyll and carotenoid analyses}

Protein content was determined following the Bradford protein assay [12]. Cellular chlorophyll and carotenoid isolations were achieved with the methanol extraction method; chlorophyll and carotenoid contents were calculated according to the formula for methanol extraction described by Lichtenthaler [13].

\subsection{GC-MS fatty acid profile determination}

$1 \%(\mathrm{~V} / \mathrm{V})$ dilutions of each oil sample dissolved in chloroform were subjected to GC/MS analysis by injecting $2 \mu \mathrm{L}$ sample into a Rtx ${ }^{\mathrm{B}}$-5MS fumed silica column (30 m, $0.25 \mathrm{~mm}$ ID, $0.10 \mu \mathrm{m} . \mathrm{df})$. The injection temperature was set to $200^{\circ} \mathrm{C}$ and column temperature program began at $50^{\circ} \mathrm{C}$ for $5 \mathrm{~min}$. Column temperature was further increased by $15^{\circ} \mathrm{C} / \mathrm{min}$ to $300^{\circ} \mathrm{C}$ where it was kept for 5 min to complete the run. The GC was coupled to a quadrupole mass spectrometer, the interface temperature and ion source temperature was adjusted to $280^{\circ} \mathrm{C}$. MS analysis was started at 2.5 min which was set to solvent cut time.

\section{Results and discussion}

3.1. Growth analysis of S. obliquus cultivated under different nitrogen sources

Utilization of different nitrogen sources and their effects on cell growth, lipid accumulation and fatty acid profile of green alga $S$. obliquus were analyzed. Previous studies have demonstrated the influence of altered nutrient conditions on biomass and lipid productivity in various algae species [14-16]. According to the previous findings, the strategy of altering nutrient conditions especially limitations of nitrogen and phosphorus may result in increased lipid accumulation; however fatty acid profiles generally were not determined under experimented conditions in most studies. Green alga $S$. obliquus was selected for this study because several studies have demonstrated the alga as a promising species in biodiesel production $[10,11]$. This study showed that different nitrogen source utilization results in altered lipid accumulation besides significantly changed fatty acid profile in
S. obliquus suggesting that altered nutrient conditions might be also one of the important factors for deciding biodiesel quality.

All tested nitrogen sources were found to be successfully promoting growth of $S$. obliquus as shown in Fig. 1. According to the results, specific growth rates were found to be $0.34,0.32$, and 0.37 for $\mathrm{NaNO}_{3}, \mathrm{NH}_{4} \mathrm{Cl}$ and urea experimental groups. The best biomass concentration was found under urea regime which was $659 \mathrm{mg} / \mathrm{L}$, compared with $272 \mathrm{mg} / \mathrm{L}$ and $524 \mathrm{mg} / \mathrm{L}$ for $\mathrm{NH}_{4} \mathrm{Cl}$ and $\mathrm{NaNO}_{3}$ regimes, respectively. Doubling times were found as 2.06, 2.14, and 1.90. Divisions per day of different groups were found as $0.49,0.47$, and 0.53 in the order of $\mathrm{NaNO}_{3}$, $\mathrm{NH}_{4} \mathrm{Cl}$ and urea regimes.

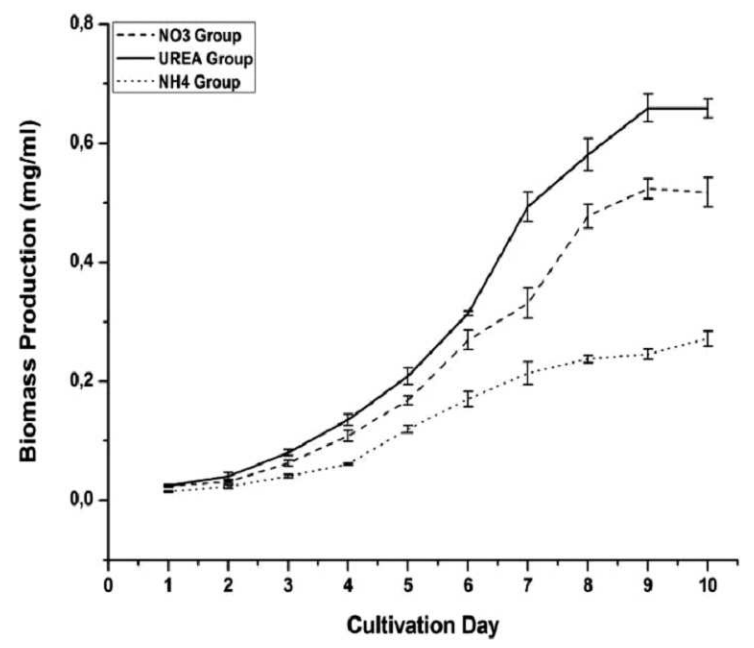

Fig. 1. Growth analysis of S. obliquus cultivated under different nitrogen regimes. Data are presented as the mean value of triplicates with \pm error bars.

3.2. Gravimetric, fluorometric and flow-cytometric lipid content analysis of $\mathrm{S}$. obliquus cultivated under different nitrogen sources

Nitrogen depletion is well-known factor which increases lipid production in many algal species shown in various studies [10, 14-16], however relatively low information has been presented about different nitrogen source utilization and the effects on cellular metabolic response. Therefore, we focused specifically on the influence of different nitrogen source utilization.

Microalgae biomass was harvested after ten days of cultivation and subjected to lipid extraction for gravimetric lipid content analysis. The biomass obtained from $\mathrm{NH}_{4} \mathrm{Cl}$ group has the highest lipid content, $25.6 \%$, followed by $19.7 \%$, and $11.04 \%$ for $\mathrm{NaNO}_{3}$ and urea medium, respectively, seen in Fig. 2. The nile-red fluorometric assay was previously shown to be a powerful method for comparing lipid contents of many tissues and various cells of different organisms, especially algal species [17-20]. After ten days of cultivation, cells were harvested, stained with nile-red fluorometric dye, and subjected to 96 -well 
microplate fluorometric assay. In accordance with the gravimetric lipid content measurements, results obtained from fluorometric assays showed similar results seen also in Fig. 2. According to the results, gravimetric and fluorometric methods are significantly correlated and support each other with significant $R^{2}$ values.

According to Li et al., $N$. oleoabundans has the best lipid accumulation under $\mathrm{NaNO}_{3}$ regime [9]. Lin et al. [14] demonstrated that $S$. rubescens like microalgae accumulated more fatty acid methyl esters (FAME) under $\left(\mathrm{NH}_{4}\right)_{2} \mathrm{CO}_{3}-\mathrm{N}$ regime. Moreover, $\mathrm{NaNO}_{3}$ was not the most favorable nitrogen source both in biomass and FAME productivity [14]. Under the light of previous studies, it can be discussed that each algal species may utilize different nitrogen source and demonstrate different lipid and biomass productivities besides different fatty acid profiles under different nitrogen regimes. Here, it is reported that a slight decrease in biomass productivity of the $\mathrm{NH}_{4} \mathrm{Cl}$ group was found and lipid productivity of S. obliquus was demonstrated to be higher than that of other tested nitrogen sources.
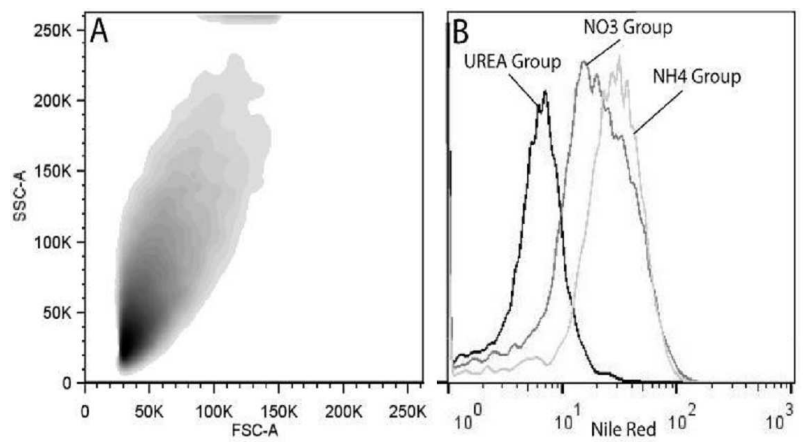

Fig. 2. Representative data of flow-cytometric lipid content analysis of $S$. obliquus cultivated under different nitrogen regimes. (A) Forward scatter (FSC) histogram of analyzed S. obliquus cells $11 \%$ of total particles were determined as viable cells based on their cellular size and granulation and further analyzed in terms of their lipid contents. (B) Histogram of flow-cytometric analysis of lipid contents of $S$. obliquus cells cultivated with $5 \mathrm{mM}$ urea (black line), $\mathrm{NaNO}_{3}$ (gray line), and $\mathrm{NH}_{4} \mathrm{Cl}$ (light gray line). Experiments were done in triplicates for each experimental group.

The use of flow-cytometric analysis for determination of lipid accumulations in algae cells were successfully shown in previous studies [21]. Because gravimetric and microplate fluorometric analyses could not give information about the single cell level, flow-cytometric analysis was also conducted for determination of the response of single cells. Results shown in Fig. $3 \mathrm{NH}_{4} \mathrm{Cl}$ regime resulted in increased lipid accumulation compared to other tested nitrogen sources, $\mathrm{NaNO}_{3}$ and urea.

For a successful lipid comparison in algae cells, different methodologies should be used in combinatory manner and support to each other. Each of the three different methods used in this study has their own advantages

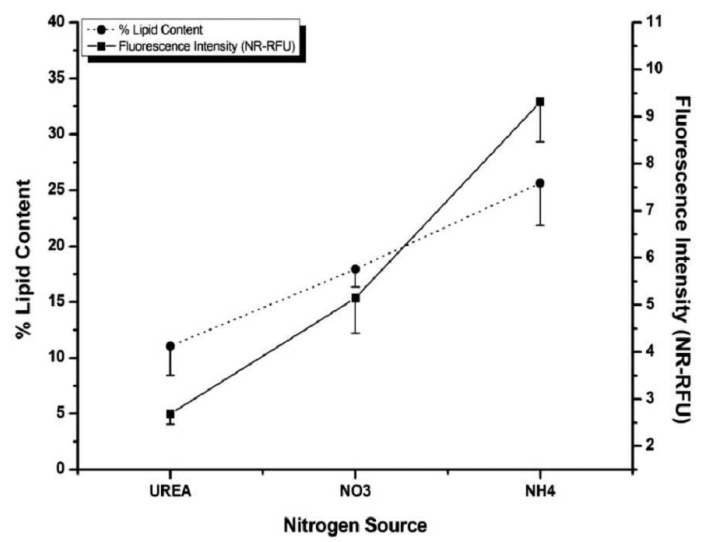

Fig. 3. Lipid content analysis of S. obliquus cultivated under different nitrogen regimes. Data represent the \% lipid contents of $S$. obliquus cultivated with different nitrogen sources and 96-well microplate fluorometric nilered staining analysis represented as relative fluorescent units. Data are presented as the mean value of triplicates with \pm error bars.

and disadvantages. For the gravimetric method, quantifying cellular lipid content is mostly time consuming process. It requires the extraction of lipid from a high amount of cellular biomass using dangerous organic solvents such as hexane or chloroform, evaporation of the solvents, and determination of the amount of lipid by weighing the dried extract, which might not be precise due to technical bottlenecks.

Fluorometric measurements may be more robust for determination of cellular lipid content if a suitable lipid standard is able to be used. Nevertheless, optimization of lipid standard is difficult, and even if standard curves are of good quality, the fluorometric technique would not give the precise in vivo lipid content of cells. If lipids were extracted from cells and allowed to form micelles in aqueous solutions, lipid standards would give more accurate results with fluorometric methods. Some studies have proposed techniques using lipid standards for fluorometric algal lipid content analyses [20].

What is more, regarding the 96-well microplate fluorometric method, it is very important to avoid cell clustering due to stress conditions, as the difference between emissions from single and clustered cells would lead to misleading measurements. Also there is no way to separate living and dead cells during measurements. For this reason, flow-cytometric analysis has advantages over other techniques such as the possibility of characterizing and separating subpopulations, distinguishing between living and dead cells during measurements, and the ability to measure at the single cell level and avoid misreading of clustered cells. However, flow-cytometry might not be suitable for all algal species, especially not for filamentous species which do not have round and well-shaped cellular morphology; moreover, the doubling effect must be avoided during measurements for correct readings. 
In order to prevent possible misleading, results from the weaknesses were mentioned for each method. In this study, gravimetric, fluorometric and flow-cytometric techniques were all used for better and precise comparison of cellular responses of green alga $S$. obliquus in terms of lipid accumulation. In addition, $S$. obliquus cells were successfully subjected to flow-cytometric nile-red analysis because of its suitable, unicellular morphological characteristics. Such features easing high-throughput analysis methods are crucial for fast and reliable selection of algal species/strains for biodiesel production.

\subsection{Pigment and protein analysis of S. obliquus cultivated under different nitrogen sources}

It is known that nitrogen conditions affect all metabolic processes including lipid, protein, and pigment synthesis in algae species [22]. From this rationale, chlorophyll, carotenoid, and protein analyses were also conducted to better understand the effects of different nitrogen sources on important metabolic processes shown in Fig. 4. According to the results, chlorophyll a, chlorophyll b, and total carotenoid contents for the $\mathrm{NaNO}_{3}$ group were found to be $0.30-0.19-0.04 \mu \mathrm{g} / \mathrm{gfw}$, respectively, the same pigment contents for the $\mathrm{NH}_{4} \mathrm{Cl}$ group was found to be $0.23-0.13-0.05 \mathrm{\mu g} / \mathrm{gfw}$, and finally for the urea group chlorophyll $\mathrm{a}-\mathrm{b}$ and carotenoid contents were determined as $0.41-0.24-0.04 \mathrm{\mu g} / \mathrm{gfw}$ in the same manner. Total protein contents were found to be $0.28 \mu \mathrm{g} / \mu \mathrm{L}$, $0.21 \mathrm{\mu g} / \mathrm{\mu L}$ and $0.33 \mathrm{\mu g} / \mu \mathrm{L}$ corresponding to $53 \%, 36 \%$ and $60 \%$ in terms of cellular protein contents for $\mathrm{NaNO}_{3}$, $\mathrm{NH}_{4} \mathrm{Cl}$ and urea, respectively.

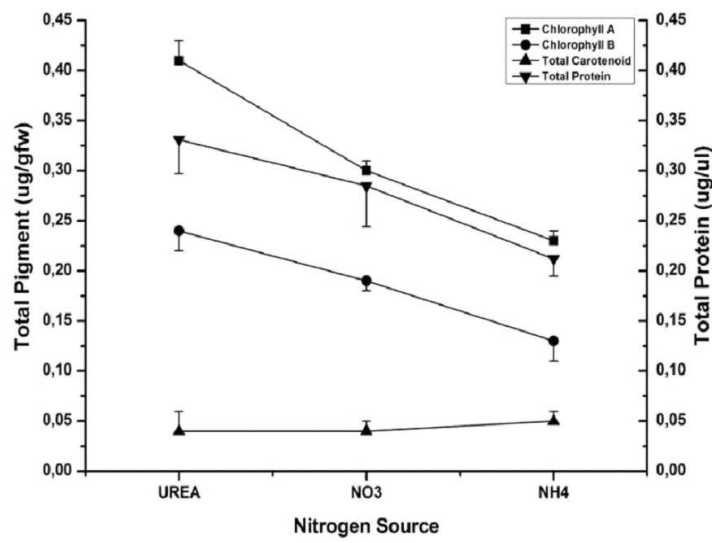

Fig. 4. Protein and pigment content analysis of $S$. obliquus cultivated under different nitrogen regimes. Data present the mean value of each triplicate represented as $\mu \mathrm{g} / \mathrm{gfw}$ (microgram per gram fresh weight) and $\mu \mathrm{g} / \mu \mathrm{l}$ with \pm error bars for pigments and total protein contents, respectively.

Algae species can utilize different inorganic and organic substances as nitrogen sources [23, 24]. Therefore, green alga $S$. obliquus also could successfully use $\mathrm{NaNO}_{3}$, $\mathrm{NH}_{4} \mathrm{Cl}$ and urea. Chlorophyll a-b and protein contents shown in Fig. 4 demonstrate the successful utilization of all tested nitrogen sources. Total carotenoid synthesis was found slightly increased upon increased level of lipid accumulation in $\mathrm{NH}_{4} \mathrm{Cl}$ group compared to other tested nitrogen sources which may indicate a crosstalk between carotenoid and lipid synthesis.

\section{4. $G C-M S$ analysis of S. obliquus cultivated under different nitrogen sources}

Polyunsaturated fatty acids containing four or more double bonds are common in microalgae lipids. These bonds can be oxidized easily during storage, reducing the acceptability of microalgae oil for production of biodiesel. In contrast, Mandal et al. demonstrated that the biodiesel from $S$. obliquus contains mainly saturated and mono-unsaturated fatty acids $(\approx 75 \%$ of the total fatty acyl methyl esters), which grants that oil obtained from $S$. obliquus has higher oxidative stability [11]. Thus, $S$. obliquus should be considered as a potential organism for biodiesel production. Another study concluded that if the purpose is to produce biodiesel from one algal species, $S$. obliquus presents the most adequate fatty acid profile [25]. On the basis of the previous studies, it was characterized that the fatty acid profiles of $S$. obliquus cultivated with different nitrogen sources by using GCMS. For each oil sample, individual fatty acid percentages

TABLE I

Fatty acid profiles of $S$. obliquus cultivated with $\mathrm{NaNO}_{3}$, $\mathrm{NH}_{4} \mathrm{Cl}$ and urea as nitrogen sources. Data are presented as the mean value of triplicates with \pm errors.

\begin{tabular}{|c|c|c|}
\hline Type & fraction [\%] & Total [\%] \\
\hline \multicolumn{3}{|c|}{$\mathrm{NaNO}_{3}$} \\
\hline $\mathrm{C} 16+0$ & $5.54 \pm 0.2$ & \\
\hline $\mathrm{C} 16+1$ & $1.70 \pm 0.05$ & \\
\hline $\mathrm{C} 17+0$ & $5.73 \pm 0.09$ & saturated \\
\hline $\mathrm{C} 18+0$ & $34.32 \pm 1$ & $73.75 \pm 2.06$ \\
\hline $\mathrm{C} 19+0$ & $0.95 \pm 0.07$ & \\
\hline $\mathrm{C} 19+1$ & $9.03 \pm 0.6$ & unsaturated \\
\hline $\mathrm{C} 19+2$ & $10.60 \pm 0.5$ & $26.25 \pm 1.17$ \\
\hline $\mathrm{C} 20+0$ & $27.19 \pm 0.7$ & \\
\hline $\mathrm{C} 22+1$ & $4.90 \pm 0.02$ & \\
\hline \multicolumn{3}{|c|}{$\mathrm{NH}_{4} \mathrm{Cl}$} \\
\hline $\mathrm{C} 17+0$ & $9.50 \pm 0.5$ & \\
\hline $\mathrm{C} 17+3$ & $0.27 \pm 0.03$ & saturated \\
\hline $\mathrm{C} 18+0$ & $39.18 \pm 0.2$ & $76.98 \pm 1.4$ \\
\hline $\mathrm{C} 18+2$ & $1.50 \pm 0.09$ & \\
\hline $\mathrm{C} 19+2$ & $13.28 \pm 2$ & unsaturated \\
\hline $\mathrm{C} 19+3$ & $13.32 \pm 0.1$ & $23.02 \pm 2.22$ \\
\hline $\mathrm{C} 20+0$ & $30.22 \pm 0.7$ & \\
\hline \multicolumn{3}{|c|}{ Urea } \\
\hline $\mathrm{C} 17+0$ & $7.72 \pm 0.3$ & \\
\hline $\mathrm{C} 17+3$ & $0.47 \pm 0.01$ & saturated \\
\hline $\mathrm{C} 18+0$ & $36.28 \pm 1.2$ & $72.53 \pm 3.1$ \\
\hline $\mathrm{C} 18+2$ & $2.66 \pm 0.09$ & \\
\hline $\mathrm{C} 19+2$ & $12.49 \pm 1$ & unsaturated \\
\hline $\mathrm{C} 19+3$ & $11.82 \pm 0.9$ & $27.47 \pm 2$ \\
\hline $\mathrm{C} 20+0$ & $28.52 \pm 1.6$ & \\
\hline
\end{tabular}


were estimated from total integrated peak areas. Irrelevant peaks were not included to the calculations. As shown in Table I, total saturated fatty acid percentages are much higher than those of unsaturated fatty acids in each experimental group which is supported by previous studies. This result indicates that oil extracted from $S$. obliquus has higher oxidative stability. Data also indicates that fatty acid profiles are significantly divergent under different nitrogen regimes, especially $\mathrm{NH}_{4} \mathrm{Cl}$ group demonstrates slightly different profile compared to $\mathrm{NaNO}_{3}$ and urea groups. Last of all C18:0 and C20:0 were found as the most abundant oil types in all samples which demonstrate an appropriate oil characteristic for biodiesel production under all tested nitrogen regimes.

\section{Conclusions}

S. obliquus is a suitable species for manufacturing biodiesel, and therefore optimizing the cultivation process of this species is a worthwhile activity. The results obtained from this study show that $\mathrm{NaNO}_{3}, \mathrm{NH}_{4} \mathrm{Cl}$ and urea can be successfully utilized for growth of the green alga $S$. obliquus. $\mathrm{NH}_{4} \mathrm{Cl}$ was found to result in increased lipid accumulation compared to alternative nitrogen sources $\mathrm{NaNO}_{3}$ and urea under investigated conditions. Furthermore, fatty acid profiles show differences under different nitrogen regimes especially in $\mathrm{NH}_{4} \mathrm{Cl}$ regime. In addition, flow-cytometric and microplate nilered fluorescent assays for the determination of lipid contents of algae were verified to be high-throughput, fast and reliable methods. For industrial applications, such studies could be scaled-up and repeated in photo bioreactors and open-cultivation conditions. Other nitrogen sources might be also examined so as to see the differences in growth and lipid accumulation responses.

\section{References}

[1] Y. Chisti, Biotechnol. Adv. 25, 294 (2007).

[2] B.J. Krohn, C.V. McNeff, B. Yan, D. Nowlan, Biores. Technol. 102, 94 (2011).

[3] A. Singh, P.S. Nigam, J.D. Murphy, Biores. Technol. 102, 10 (2011).

[4] P. Metzger, C. Largeau, Appl. Microbiol. Biotechnol. 66, 486 (2005).
[5] S.Y. Chiu, C.Y. Kao, M.S. Tsai, S.C. Ong, C.Y. Chen, C.S. Lin, Biores. Technol. 100, 833 (2009).

[6] W. Chen, C. Zhang, L. Song, M. Sommerfeld, Q. Hu, J. Microbiol. Meth. 77, 41 (2009).

[7] M.C. Damiani, C.A. Popovich, D. Constenla, P.I. Leonardi, Biores. Technol. 101, 3801 (2010).

[8] Z.Y. Liu, G.C. Wang, B.C. Zhou, Biores. Technol. 99, 4717 (2008).

[9] Y. Li, M. Horsman, B. Wang, N. Wu, C.Q. Lan, Appl. Microbiol. Biotechnol. 81, 629 (2008).

[10] S.H. Ho, W.M. Chen, J.S. Chang, Biores. Technol. 101, 8725 (2010)

[11] S. Mandal, N. Mallick, Appl. Microbiol. Biotechnol. 84, 281 (2009).

[12] M.M. Bradford, Anal. Biochem. 72, 248 (1976).

[13] H.K. Lichtenthaler, Meth. Enzymol. 148, 350 (1987).

[14] Q. Lin, J. Lin, Biores. Technol. 102, 1615 (2011).

[15] C.H. Hsieh, W.T. Wu, Biores. Technol. 100, 3921 (2009).

[16] L. Xin, H.Y. Hu, G. Ke, Y.X. Sun, Biores. Technol. 101, 5494 (2010).

[17] M. Romek, B. Gajda, E. Krzysztofowicz, M. Kepczynski, Z. Smorag, Theriogenology 75, 42 (2011).

[18] M. Siaut, S. Cuine, C. Cagnon, B. Fessler, M. Nguyen, P. Carrier, A. Beyly, F. Beisson, C. Triantaphylides, Y. Li-Beisson, G. Peltier, BMC Biotechnology 11, 7 (2011).

[19] T.L. da Silva, A. Reis, E. Medeiros, A.C. Oliveira, L. Gouveia, Appl. Biochem. Biotechnol. 159, 568 (2009).

[20] M. Chen, H. Tang, H. Ma, T.C. Holland, K.Y. Ng, S.O. Salley, Biores. Technol. 102, 1649 (2011).

[21] A. de la Jara, H. Mendoza, A. Martel, C. Molina, L. Nordströn, V. de la Rosa, R. Díaz, J. Appl. Phycol. 15, $433(2003)$

[22] L.M. Colla, T.W. Bertolin, J.A.V. Costa, Z. Naturforsch. C J. Biosci. 59, 55 (2004).

[23] T. Ietswaart, P.J. Schneider, R.A. Prins, Appl. Environm. Microbiol. 60, 1554 (1994).

[24] C.G. Liu, X.C. Jin, L. Sun, H.W. Sun, L. Zhu, Y. Yu, S.G. Dai, Y.Y. Zhuang, Huan Jing Ke Xue 27, 101 (2006).

[25] L. Gouveia, A.C. Oliveira, J. Indian Microbiol. Biotechnol. 36, 269 (2009). 